\title{
In Vitro Evaluation of Radioprotective and Radiosensitizing Effects of Rituximab
}

\author{
Nirav S. Kapadia ${ }^{1}$, James M. Engles ${ }^{2}$, and Richard L. Wahl ${ }^{2}$ \\ ${ }^{1}$ School of Medicine, The Johns Hopkins University, Baltimore, Maryland; and ${ }^{2}$ Division of Nuclear Medicine, Russell H. Morgan \\ Department of Radiological Sciences, School of Medicine, The Johns Hopkins University, Baltimore, Maryland
}

Clinical radioimmunotherapies with anti-CD20 monoclonal antibodies involve administering a predose of unlabeled anti-CD20 antibodies to favorably alter the biodistribution profile of the subsequently administered radiolabeled antibodies and mediate antitumor effects. Prior in vitro data suggested that unlabeled antiCD20 monoclonal antibodies radiosensitize lymphoma cells as well. We assessed the antiproliferative and possible radiosensitizing capabilities of an anti-CD20 monoclonal antibody, rituximab. Methods: Luciferase-transfected (via a lentivirus vector) $\mathrm{CD} 2 \mathrm{O}^{+}$ human Raji lymphoma cells in log-phase growth were incubated with or without rituximab $(20 \mu \mathrm{g} / \mathrm{mL})$ for either 1 or $24 \mathrm{~h}$ before external-beam radiation exposure. Cell counts were measured with a luciferase assay at 24-h intervals. Subsets of these cells were also analyzed for cell cycle status by flow cytometry. Results: Rituximab pretreatment and irradiation were found to significantly inhibit tumor cell growth compared with irradiation alone (by a factor of 0.40 at $1 \mathrm{~Gy}[P<0.01])$. One hour of rituximab pretreatment modestly radiosensitized tumor cells at a radiation dose of 1 Gy (by a factor of 1.03 compared with the results for nonirradiated cells). At higher radiation doses ( 2 and 12 Gy), $1 \mathrm{~h}$ of rituximab pretreatment paradoxically radioprotected tumor cells by factors of $0.25(P<0.01)$ and $0.54(P<0.05)$, respectively. Rituximab predosing for $24 \mathrm{~h}$ was found to be radiosensitizing at a radiation dose of $4 \mathrm{~Gy}$ (by a factor of $2.84[P<0.01]$ ) but radioprotective at radiation doses of 1,8 , and 12 Gy (by factors of $0.10[P<0.01], 2.50[P<0.01]$, and $2.07[P<0.05]$, respectively). These results correlated with retardation of the cell cycle at $6 \mathrm{~d}$ after rituximab administration, as determined by flow cytometry. Conclusion: Rituximab demonstrated a direct tumor antiproliferative effect in the absence of radiation. At lower levels of radiation exposure, rituximab radiosensitized Raji lymphoma cells. At higher doses of radiation, rituximab paradoxically protected tumor cells against ionizing radiation, possibly through effects on the cell cycle. These radiobiologic effects of rituximab should be carefully considered in the design of radioimmunotherapeutic trials.

Key Words: rituximab; radiosensitization; radioprotection; radioimmunotherapy

J Nucl Med 2008; 49:674-678

DOI: $10.2967 /$ jnumed.107.043752

\footnotetext{
Received Jun. 19, 2007; revision accepted Dec. 13, 2007.

For correspondence or reprints contact: Richard L. Wahl, MD, Division of Nuclear Medicine, Russell H. Morgan Department of Radiological Sciences, School of Medicine, The Johns Hopkins University, 601 N. Caroline St., Room 3223, Baltimore, MD 21287-0817.

E-mail: rwahl@jhmi.edu

COPYRIGHT @ 2008 by the Society of Nuclear Medicine, Inc.
}

$\mathbf{U}$ nlabeled anti-CD20 antibodies have been shown to mediate antitumor effects in animal model systems for several decades (1). Rituximab, an anti-CD20 chimeric, recombinant monoclonal antibody, is one such antibody. First described in 1994 (2), its use and efficacy in treating nonHodgkin's lymphoma have been established such that it was granted U.S. Food and Drug Administration approval for non-Hodgkin's lymphoma therapy 3 y later. Although the precise in vivo mechanism of anti-CD20 antibodies is not completely understood, in vitro data suggest that they exert their effects through antibody-dependent cellular cytotoxicity (3), direct activation of apoptosis $(4,5)$, cell-mediated cytotoxicity $(6,7)$, or cell cycle arrest $(8)$. In addition to their use in various chemotherapeutic approaches for lymphoma, anti-CD20 antibodies are also the main elements of the only 2 U.S. Food and Drug Administration-approved radioimmunotherapeutic regimens (9).

Radioimmunotherapy (RIT) involves the targeting of a radioactive monoclonal antibody to selectively deliver ionizing radiation directly to tumors. At present, 2 approved agents are available: tositumomab and ${ }^{131}$ I-tositumomab (Bexxar; GlaxoSmithKline) and ${ }^{90}$ Y-ibritumomab tiuxetan (Zevalin; Cell Therapeutics, Inc.). Protocols for both agents take into consideration the need to decrease the specific sequestration of labeled antibodies by highly accessible "antigen sinks," including the spleen and circulating CD20+ lymphocytes. Predosing with unlabeled antibodies prevents unwanted normal-tissue toxicity by making the biodistribution profile of radiolabeled antibodies more predictable, decreasing their clearance rates (10) and increasing their percentage injected dose $(11,12)$. However, an important radiobiologic question arises: Can such an anti-CD20 monoclonal antibody predose affect the radiosensitivity of targeted tumor cells?

Although rituximab has been reported to be a radiosensitizing agent, to date there are limited data supporting this report (13). As mentioned earlier, a purported mechanism of anti-CD20 antibody action is arrest of the cell cycle (8). We hypothesized that if rituximab arrests lymphoma cells in the radioresistant $G_{0} / G_{1}$ phase of the cell cycle (14), then it may be radioprotective.

The aim of the present study was to determine whether there were any clear radioprotective or radiosensitizing 
effects of rituximab at expected concentrations in serum before exposure to various single-fraction external-source radiation doses. Cell growth assays with selective cell cycle analyses were performed to determine whether and by what mechanism rituximab predosing might affect the radiosensitivity of Raji lymphoma cells.

\section{MATERIALS AND METHODS}

\section{Cells and Cell Culture}

Epstein-Barr virus-infected Raji lymphocyte tumor cells transfected via a lentivirus vector with green fluorescent protein (GFP) and luciferase were established by Dr. Zhaohui Ye in collaboration with the laboratory of Dr. Linzhao Cheng at The Johns Hopkins University (Figs. 1A and 1B) (15). A total of $10^{5}$ cells in the exponential phase of growth were incubated in $10 \mathrm{~mL}$ of CellGro RPMI medium (Mediatech) containing 10\% fetal bovine serum (Hyclone) and 1\% penicillin-streptomycin (Invitrogen Corp.) over a total of $6 \mathrm{~d}$ and maintained at $37^{\circ} \mathrm{C}$ with $5 \% \mathrm{CO}_{2}$ (in a Forma Series II Water-Jacketed Incubator; Thermo Fisher Scientific Inc.). Cells were plated in triplicate.

\section{Cell Viability Assay}

Cells were initially counted with a BrightLine hemocytometer (Reichert), and cell counts obtained in this manner were then correlated with luciferase activity. In brief, luciferin (MIP) was added to a known quantity of cells, and the mixture was incubated in the dark for 2 min before $30 \mathrm{~s}$ of photon counting with a Monolight 3010 luminometer (Pharmingen/Becton-Dickinson) in accordance with the manufacturer's instructions. Standard curves were generated in this manner to ensure that a linear measurement was available over the ranges of the cells to be studied $\left(3 \times 10^{1}-3 \times\right.$ $10^{6}$ cells per milliliter). After verification of the standard curves, cells were counted with the luciferase assay at 24-h intervals for $6 \mathrm{~d}$. All experiments were performed in triplicate.

\section{Cell Growth Rate}

The cell growth rate was determined by averaging the slopes of cell growth data on the most linear portion of the plot (with a logarithmic vertical axis). This plot corresponded to sections of the growth curve between days 1 and 5, with $R^{2}$ values generally in the range of $0.90-0.99$.

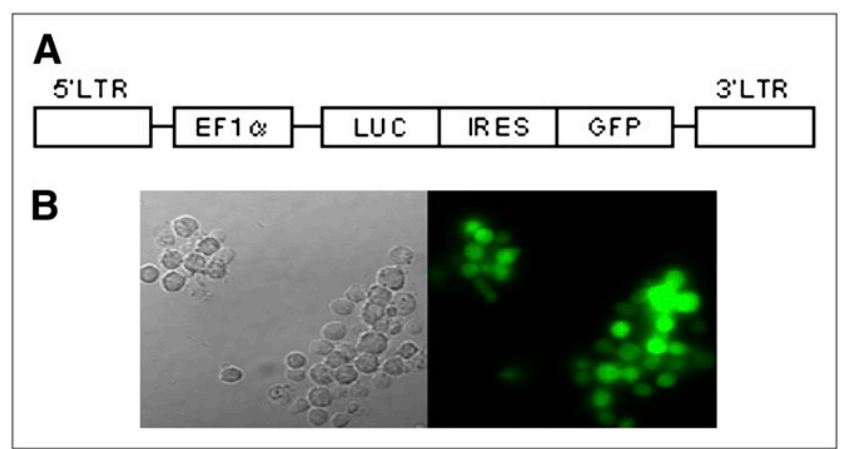

FIGURE 1. (A) Lentivirus transfection cassette. (B) Fluorescence microscopy of transfected cells, demonstrating stable GFP expression. EF $1 \alpha=$ elongation factor $1 \alpha$; IRES $=$ internal ribosome entry site; $5^{\prime} \mathrm{LTR}=5^{\prime}$ long terminal repeat; $3^{\prime} \mathrm{LTR}=$ $3^{\prime}$ long terminal repeat; LUC = luciferase.

\section{Antibody}

Pharmaceutical-grade rituximab (Genentech/Biogen IDEC Corp.) was kindly provided by the Sidney J. Kimmel Cancer Center at The Johns Hopkins University and stored at $4^{\circ} \mathrm{C}$. Sodium dodecyl sulfate-polyacrylamide gel electrophoresis was used to confirm the presence of intact, 150-kDa antibody molecules. Raji lymphoma cell surface expression of CD20 and antibody immunoreactivity were verified with a quantitative CD20 assay followed by a competitive inhibition assay (antibody source: Quantibrite CD20 PE; BD Biosciences) performed by use of a FACS-Caliber quantitative flow cytometer (Becton-Dickinson Immunocytometry Systems). A rituximab dose of $20 \mu \mathrm{g} / \mathrm{mL}$ was administered to cells either 1 or $24 \mathrm{~h}$ before irradiation in accordance with expected peak levels in serum given current dosing strategies.

\section{Radiation}

Transfected Raji lymphoma cells that were either not treated or treated with rituximab were either not exposed or exposed to various amounts of external-source cesium-based $\gamma$-radiation (none, $1 \mathrm{~Gy}, 2$ Gy, 4 Gy, 8 Gy, or 12 Gy) on a Gammacell 3000 Elon apparatus (MDS-Nordian). Ionizing radiation was delivered at a rate of 5 $\mathrm{Gy} / \mathrm{min}$. Control cells that were not irradiated were removed from the incubator and transported to the radiation site for the period of irradiation of the other cells.

\section{Cell Cycle Analysis}

Cell cycle status was assayed at $5 \mathrm{~d}$ after irradiation with a Vybrant Violet DyeCycle apparatus (Invitrogen Probes) in accordance with the manufacturer's instructions. An LSRII flow cytometer (Becton-Dickinson Immunocytometry Systems) was used to quantitate cellular DNA; the resulting data were used to establish the cell cycle status. Gating was set in accordance with the manufacturer's instructions, with the single largest peak among the nonirradiated (control) cells being calibrated to cells with 2N DNA (normally occurring diploid DNA seen in nondividing cells) and the next largest peak being calibrated to cells with 4N DNA (tetraploid DNA seen in cells after DNA replication but before cell division). Interval areas under the curve were determined by an individual who was experienced in flow cytometry and were kept constant between samples.

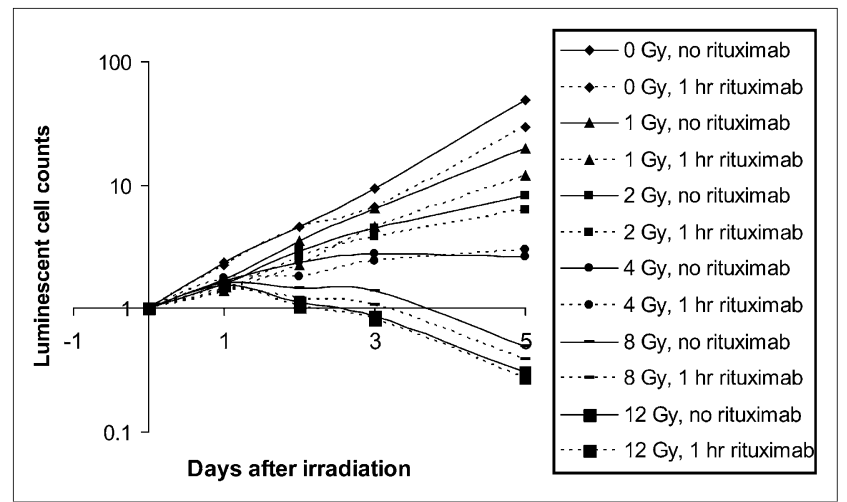

FIGURE 2. Effect of 1 -h rituximab predose $(20 \mu \mathrm{g} / \mathrm{mL})$ on cell survival. Dose-response relationship was observed with regard to cell growth rate in response to various amounts of radiation exposure. Each data point is normalized to starting cell count and represents mean of 3 determinations. 


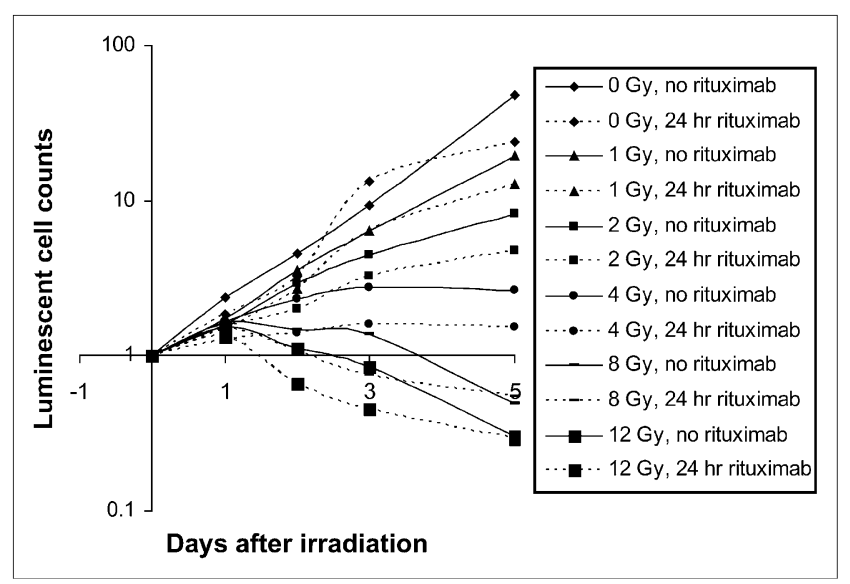

FIGURE 3. Effect of 24-h rituximab predose on cell survival. Dose-response relationship was observed with various amounts of radiation exposure. Each data point is normalized to cell count at day of irradiation and represents mean of 3 determinations.

\section{RESULTS}

\section{Antiproliferative Effect}

A clear dose-response effect was observed across samples over the 5-d observation period (Figs. 2 and 3). At levels of 8 and $12 \mathrm{~Gy}$, an overall death of cells to below starting cell numbers was observed by day 5 . In a comparison of samples receiving rituximab and control samples, there was a statistically significant decrease in cell survival at most levels of radiation when rituximab was added (Table 1 and Figs. 2 and 3 ). However, at the highest doses of radiation, the addition of rituximab proffered no additional benefit in terms of overall cell killing.

\section{Cell Growth Rate}

A clear dose-response relationship was also evident with regard to the rate of cell growth and increasing levels of radiation (Table 2). With no radiation, $1 \mathrm{~Gy}, 2 \mathrm{~Gy}$, and $4 \mathrm{~Gy}$ of radiation, both 1 - and 24 -h rituximab predosing significantly decreased the rate of cell growth compared with the results for cells that were exposed to similar radiation doses in the absence of rituximab. At 8 and 12 Gy, however, 24-h rituximab predosing significantly decreased the overall rate of cell death compared with the results for cells that were irradiated at similar radiation doses but were not exposed to rituximab $(P<0.01$ and $P<0.05$, respectively).

\section{Cell Cycle Analysis}

At $5 \mathrm{~d}$ after irradiation, nonirradiated cells demonstrated a modest but statistically significant increase in the percentage of cells in the $G_{0} / G_{1}$ phase when rituximab was administered $24 \mathrm{~h}$ before irradiation (Table 3 ). This finding correlated with a statistically significant decrease in the percentage of cells in the $\mathrm{S}$ and $\mathrm{G}_{2} / \mathrm{M}$ phases. Among cells exposed to $1 \mathrm{~Gy}$ of radiation, a modest trend toward a decreased percentage of cells in the $\mathrm{S}$ phase was observed, and at $8 \mathrm{~Gy}$ of radiation, there was again a modest but statistically significant increase in the percentage of cells in the $\mathrm{G}_{0} / \mathrm{G}_{1}$ phase. There was also a statistically significant decrease in polyploidy among cells receiving $8 \mathrm{~Gy}$ of radiation and rituximab compared with the results for control cells. Among cells receiving 12 Gy of radiation, no differences in the cell cycle were observed between cells receiving rituximab and control cells. However, a large number of hyperdiploid cells were seen.

\section{DISCUSSION}

The purpose of these in vitro experiments was to determine whether rituximab was protective, sensitizing, or noncontributive to the net effect of single-fraction external-beam radiation therapy given at low and high levels. In our first set of experiments, cells were administered rituximab at $20 \mu \mathrm{g} /$ $\mathrm{mL}$ in combination with increasing doses of radiation and were compared with control cells, which received radiation only. With regard to the experimental design, we were reassured to find that the baseline radiosensitivity of our GFP- and luciferase-transfected (via a lentivirus vector) Raji cells was unchanged with respect to prior published data on the radiosensitivity of nontransfected Raji cells, albeit measured through different methods (16). The dose of rituximab administered was calculated from the known pharmacokinetic parameters of rituximab (17) and fell in the midrange of

TABLE 1

Absolute Cell Growth over 5 Days for Cells Treated with Rituximab Predose or No Predose (Control Cells)*

\begin{tabular}{|c|c|c|c|}
\hline \multirow[b]{2}{*}{$\begin{array}{l}\text { Radiation } \\
\text { dose (Gy) }\end{array}$} & \multicolumn{3}{|c|}{ Cell growth ratio at $120 \mathrm{~h}$ (cell count at day 5 compared with cell count at day 0 ) with: } \\
\hline & $\begin{array}{l}\text { No rituximab } \\
\text { (control) }\end{array}$ & $\begin{array}{l}\text { 1-h rituximab predose } \\
\text { before irradiation }(P)\end{array}$ & $\begin{array}{c}\text { 24-h rituximab predose } \\
\text { before irradiation }(P)\end{array}$ \\
\hline 0 & $48.21 \pm 26.62$ & $29.24 \pm 19.64(0.12)$ & $23.88 \pm 9.00(<0.05)$ \\
\hline 1 & $19.58 \pm 2.38$ & $11.89 \pm 4.52(<0.01)$ & $12.80 \pm 4.48(0.01)$ \\
\hline 2 & $8.26 \pm 1.30$ & $6.29 \pm 0.74(0.01)$ & $4.77 \pm 2.08(<0.01)$ \\
\hline 4 & $2.65 \pm 0.24$ & $3.02 \pm 1.30(0.40)$ & $1.54 \pm 0.32(<0.01)$ \\
\hline 8 & $0.49 \pm 0.06$ & $0.39 \pm 0.04(0.01)$ & $0.55 \pm 0.03(0.09)$ \\
\hline 12 & $0.30 \pm 0.04$ & $0.27 \pm 0.02(0.11)$ & $0.29 \pm 0.02(0.61)$ \\
\hline
\end{tabular}

*Statistically significant results are shown in boldface type. $P$ values were results of 2-tailed, paired $t$ tests comparing indicated cells against cells not treated with rituximab (control). 
TABLE 2

Mean Cell Growth Rates over 5 Days*

\begin{tabular}{|c|c|c|c|}
\hline \multirow[b]{2}{*}{$\begin{array}{l}\text { Radiation } \\
\text { dose (Gy) }\end{array}$} & \multicolumn{3}{|c|}{ Cell growth coefficient at $120 \mathrm{~h}$ (mean of logarithmic growth curve slopes) with: } \\
\hline & $\begin{array}{l}\text { No rituximab } \\
\text { (control) }\end{array}$ & $\begin{array}{l}\text { 1-h rituximab predose } \\
\text { before irradiation }(P)\end{array}$ & $\begin{array}{c}\text { 24-h rituximab predose } \\
\text { before irradiation }(P)\end{array}$ \\
\hline 0 & $0.3296 \pm 0.0211$ & $0.2814 \pm 0.0273(0.07)$ & $0.2812 \pm 0.0150(<0.05)$ \\
\hline 1 & $0.2611 \pm 0.0047$ & $0.2216 \pm 0.0114(<0.01)$ & $0.2263 \pm 0.0095(<0.01)$ \\
\hline 2 & $0.1857 \pm 0.0072$ & $0.1654 \pm 0.0048(<0.05)$ & $0.1499 \pm 0.0092(0.06)$ \\
\hline 4 & $0.0806 \pm 0.0033$ & $0.0864 \pm 0.0205(0.65)$ & $0.0351 \pm 0.0097(<0.01)$ \\
\hline 8 & $-0.1316 \pm 0.0047$ & $-0.1400 \pm 0.0101(0.27)$ & $-0.1023 \pm 0.0016(<0.01)$ \\
\hline 12 & $-0.1760 \pm 0.0062$ & $-0.1878 \pm 0.0018(<0.05)$ & $-0.1483 \pm 0.0098(<0.05)$ \\
\hline
\end{tabular}

*Statistically significant results (vs. control results) are shown in boldface type.

doses used in various inpatient clinical pharmacokinetic trials (18). The 1-h predose was chosen on the basis of the current predosing strategies for both ${ }^{131}$ I-tositumomab and ${ }^{90}$ Y-ibritumomab tiuxetan $(19,20)$. We elected to examine the effect of a longer, 24-h, predose because it would more closely model the circumstance of patients receiving rituximab in addition to external-beam therapy or patients experiencing late dose effects from RIT.

Among cells that received no radiation, there was an observed antiproliferative effect of approximately $50 \%$ when rituximab was added. Interestingly, this was the highest observed fractional antitumor effect of rituximab in our experiments. When any amount of radiation was added, only a $34 \%-42 \%$ incremental decrease in cell viability was observed. Furthermore, at 4, 8, and $12 \mathrm{~Gy}$ (under various predose conditions), there were no statistically significant antiproliferative effects of rituximab administration above those achieved with radiation alone. Although one might expect synergy between radiation and rituximab, the converse occurred as higher doses of radiation were administered.
With regard to the rates of cell growth and death in the presence of rituximab, the net effect of any rituximab predose in the absence of radiation was to decrease the rate of cell growth by $14 \%$. In terms of radiosensitization versus radioprotection, a radiosensitizer could then be described as an agent that decreases the rate of cell growth beyond $14 \%$ in the presence of radiation, and a radioprotectant could be described as an agent that exerts the reverse effect. In this regard, a $13 \%$ decrease in the rate of cell growth was observed at $1 \mathrm{~Gy}(P<0.01$ in a comparison with nonpretreated [control] cells; very modest radioprotection), a $19 \%$ decrease was observed at $2 \mathrm{~Gy}$ ( $P$ was not significant; modest radiosensitization), and a $56 \%$ decrease was observed at 4 Gy $(P<0.01$; significant radiosensitization). At levels of up to $4 \mathrm{~Gy}$, then, radiosensitizing effects appear to predominate (Table 2).

When the effect of rituximab at 8 and 12 Gy was examined, however, the trend appeared to reverse. The relative rates of cell death decreased by $22 \%$ with the addition of rituximab at $8 \mathrm{~Gy}$ and by $16 \%$ with the addition of rituximab at $12 \mathrm{~Gy}$ in

TABLE 3

Results of Cell Cycle Analyses of Various Groups of Cells Receiving Radiation, Predose of Rituximab, or Both*

\begin{tabular}{|c|c|c|c|c|c|c|}
\hline \multirow[b]{2}{*}{ Analysis } & \multirow[b]{2}{*}{$\begin{array}{l}\text { Radiation } \\
\text { dose (Gy) }\end{array}$} & \multirow[b]{2}{*}{$\begin{array}{l}\text { Rituximab } \\
\text { addition }\end{array}$} & \multicolumn{4}{|c|}{$\%$ of cells } \\
\hline & & & $\begin{array}{l}\text { In } G_{0} / G_{1} \\
\text { phase }\end{array}$ & $\begin{array}{l}\text { In S } \\
\text { phase }\end{array}$ & $\begin{array}{l}\text { In } G_{2} / M \\
\text { phase }\end{array}$ & $\begin{array}{c}\text { That were } \\
\text { hyperdiploid }\end{array}$ \\
\hline \multirow[t]{4}{*}{ Performed as indicated } & 0 & No & 56 & 35 & 7 & 2 \\
\hline & 0 & $4 \mathrm{~h}$ before analysis & 41 & 42 & 16 & 1 \\
\hline & 0 & No & 59 & 33 & 6 & 2 \\
\hline & 0 & $24 \mathrm{~h}$ before analysis & 40 & 42 & 17 & 1 \\
\hline \multirow[t]{8}{*}{ Performed $5 \mathrm{~d}$ after irradiation } & 0 & No & 58 & 29 & 12 & 1 \\
\hline & 0 & $24 \mathrm{~h}$ before irradiation & 62 & 27 & 10 & 1 \\
\hline & 1 & No & 51 & 33 & 15 & 1 \\
\hline & 1 & $24 \mathrm{~h}$ before irradiation & 54 & 31 & 14 & 1 \\
\hline & 8 & No & 12 & 34 & 24 & 30 \\
\hline & 8 & $24 \mathrm{~h}$ before irradiation & 14 & 34 & 25 & 27 \\
\hline & 12 & No & 7 & 26 & 23 & 24 \\
\hline & 12 & $24 \mathrm{~h}$ before irradiation & 7 & 24 & 25 & 44 \\
\hline
\end{tabular}

*Statistically significant results for comparison of results obtained with rituximab present and results obtained with rituximab absent at given radiation doses $(P<0.05)$ are shown in boldface type. 
comparisons with nonirradiated (control) cells. At these higher levels of radiation, it would appear that rituximab exposure somehow abrogated the cytotoxic effects of radiation (or vice versa). To seek a possible mechanistic correlate, and with an understanding of the antiproliferative effect of rituximab, we undertook an experiment to determine cell cycle status. Our hypothesis was that cell cycle inhibition potentially translated to radioprotection by stalling the cells in a less radiosensitive phase of the cell growth curve, allowing time for DNA repair to occur before replication.

The data from the cell cycle experiments provided definitive evidence that cells incubated with rituximab in vitro demonstrated a modest but nonetheless real and significant alteration in the cell cycle. This alteration resulted in a greater fraction of the cell population being present in the $G_{0} / G_{1}$ phase, resulting in fewer cells with actively replicating DNA. The prime tenet of therapeutic radiobiology involves the use of ionizing radiation to induce double-strand DNA breakage. This breakage, above all else, leads to errors during DNA replication that cause immediate cell death, or so-called "delayed induced genomic instability," which is observed as decreased viability for up to several generations after the initial radiologic insult (21). However, if cells are somehow induced to slow or even stop replication, then radiationinduced cell death would be, at the very least, negatively affected. Again, flow cytometric data demonstrated a modest but statistically significant decrease in the percentage of actively dividing cells at $6 \mathrm{~d}$ after rituximab administration. This evidence supports our hypothesis that a reduction in DNA replication radioprotects cells exposed to otherwise radioablative doses. Given the high doses experienced by cells exposed to RIT, the data discussed here suggest that a rituximab predose may result in unintended and untoward consequences with regard to the efficacy of tumor cell killing.

\section{CONCLUSION}

Although no endogenous CD20 ligand has been identified, prior data suggested that blocking the antigen with an agent such as rituximab can prevent B-cell differentiation and proliferation. It is with this idea in mind that the current sets of experiments were undertaken. For radiation to be effective, it typically requires a cell to be actively dividing before it can be killed. In the present study, we demonstrated that a decrease in the rate of cell division confers a unique advantage against the cytotoxicity of radiation. As a clinical correlate, this finding may translate into modification of the use of rituximab during immunotherapy or even exploration of the use of other (non-CD20-targeting) delivery vehicles. It is important to note, however, that the effect observed was both modest and in vitro. The effect of rituximab and radiation in vivo will undoubtedly prove more complex and thus requires further investigation.

\section{ACKNOWLEDGMENT}

Financial support was provided by SPORE-Lymphoma grant P50CA096888 from the National Cancer Institute.

\section{REFERENCES}

1. Buchsbaum DJ, Wahl RL, Normolle DP, Kaminski MS. Therapy with unlabeled and ${ }^{131}$ I-labeled pan-B-cell monoclonal antibodies in nude mice bearing Raji Burkitt's lymphoma xenografts. Cancer Res. 1992;52:6476-6481.

2. Reff M, Carner K, Chambers K, et al. Depletion of B cells in vivo by a chimeric mouse human monoclonal antibody to CD20. Blood. 1994;83:435-445.

3. Flieger D, Renoth S, Beier I, Sauerbruch T, Schmidt-Wolf I. Mechanism of cytotoxicity induced by chimeric mouse human monoclonal antibody IDECC2B8 in CD20-expressing lymphoma cell lines. Cell Immunol. 2000;204:55-63.

4. Shan D, Ledbetter JA, Press OW. Signaling events involved in anti-CD20 induced apoptosis of malignant human B cells. Cancer Immunol Immunother. 2000; 48:673-683.

5. Mathas S, Rickers A, Bommert K, Dorken B, Mapara MY. Anti-CD20 and Bcell receptor mediated apoptosis: evidence for shared intracellular signaling pathways. Cancer Res. 2000;60:7170-7176.

6. Harjunpaa A, Junnikkala S, Meri S. Rituximab (anti-CD20) therapy of B cell lymphomas: direct complement killing is superior to cellular effector mechanisms. Scand J Immunol. 2001;51:634-641.

7. Bellosillo B, Villamor N, Lopez-Guillermo A. Complement mediated cell death induced by rituximab in $\mathrm{B}$ cell lymphoproliferative disorders is mediated by a caspase-independent mechanism involving the generation of reactive oxygen species. Blood. 2001;98:2771-2777.

8. Golay J, Clark EA, Beverley PC. The CD20 (Bp35) antigen is involved in activation of B cells from the G0 to the G1 phase of the cell cycle. J Immunol. 1985;135:3795-3801.

9. Davies AJ. Radioimmunotherapy for B-cell lymphoma: Y90 ibritumomab tiuxetan and I(131) tositumomab. Oncogene. 2007;26:3614-3628.

10. Wahl RL, Zasadny KR, MacFarlane D, et al. Iodine-131 anti-B1 antibody for B-cell lymphoma: an update on the Michigan phase I experience. J Nucl Med. 1998;39(suppl):21S-27S

11. Buchsbaum DJ, Wahl RW, Glenn SD, Normolle DP, Kaminski MS. Improved delivery of radiolabeled anti-B1 monoclonal antibody to Raji lymphoma xenografts by predosing with unlabeled anti-B1 monoclonal antibody. Cancer Res. 1992;52:637-642.

12. Kaminski MS, Zasadny KR, Francis IR, et al. Radioimmunotherapy of B-cell lymphoma with $\left[{ }^{131} \mathrm{I}\right]$ anti-B1 (anti-CD20) antibody. N Engl J Med. 1993;329: $459-465$.

13. Skvortsova I, Popper BA, Skvortsov S, et al. Pretreatment with rituximab enhances radiosensitivity of non-Hodgkin's lymphoma cells. J Radiat Res (Tokyo). 2005;46:241-248.

14. Sinclair WK, Morton RA. X-ray sensitivity during the cell generation cycle of cultured Chinese hamster cells. Radiat Res. 1966;29:450-474.

15. Baba S, Cho SY, Ye Z, Cheng L, Engles JM, Wahl RL. How reproducible is bioluminescent imaging of tumor cell growth? Single time point vs. dynamic measurement approach. Mol Imaging. 2007;6:315-322.

16. Mothersill C, Seymour RJ, Seymour CB. Increased radiosensitivity in cells of two human cell lines treated with bystander medium from irradiated repairdeficient cells. Radiat Res. 2006;165:26-34.

17. Regazzi MB, Iacona I, Avanzini MA, et al. Pharmacokinetic behavior of rituximab: a study of different schedules of administration for heterogeneous clinical settings. Ther Drug Monit. 2005;27:785-792.

18. Cartron G, Blasco H, Paintaud G, Watier H, Le Guellec C. Pharmacokinetics of rituximab and its clinical use: thought for the best use? Crit Rev Oncol Hematol. 2007;62:43-52.

19. Bexxar [package insert]. Seattle, WA: Corixa Corp.; 2003.

20. Zevalin [package insert]. Cambridge, MA: Biogen IDEC Corp.; 2003.

21. Suzuki K, Ojima M, Kodama S, Watanabe M. Radiation-induced DNA damage and delayed induced genomic instability. Oncogene. 2003;22:6988-6993. 